\title{
Uma Abordagem no Ensino de Variação Linguística em uma Aplicação Educacional Aberta baseada em Hipermídia
}

\author{
Rodrigo Duarte Seabra ${ }^{1}$, Valter Pereira Romano ${ }^{2}$, Nathan Oliveira ${ }^{1}$ \\ ${ }^{1}$ Instituto de Matemática e Computação - Universidade Federal de Itajubá (UNIFEI) \\ Caixa Postal 50 - 37.500-903 - Itajubá - MG - Brasil \\ ${ }^{2}$ Centro de Letras e Ciências Humanas - Universidade Estadual de Londrina (UEL) \\ Caixa Postal 6001 - 86.057-970 - Londrina - PR - Brasil \\ rodrigo@unifei.edu.br, valter.romano@hotmail.com, oliveiranathan@gmail.com
}

\begin{abstract}
The proposed research aims to present an approach to the teaching language variation within the discipline of Portuguese. The differential of study presented here lies in the fact of the learning object produced to characterize in an open educational application with hypermedia elements and developed by a user profile no expert in technology, in this case, the teacher. The four main features of the application developed are: easy adaptation by users not experts in technology; separation of structure and content and simplicity in their adaptation according to the topic of interest; ease of learning and use of the tool, making the teacher producer of its application; and open and available content in repositories on the Internet.
\end{abstract}

Resumo. A pesquisa proposta objetiva apresentar uma abordagem sobre o ensino de variação linguística no âmbito da disciplina de língua portuguesa. O diferencial do estudo aqui apresentado reside no fato de o objeto de aprendizagem produzido se caracterizar em uma aplicação educacional aberta com elementos hipermídia e desenvolvido por um perfil de usuário não especialista em tecnologia, neste caso, o professor. As quatro principais características da aplicação elaborada são: a fácil adaptação por usuários não especialistas em tecnologia; a separação de estrutura e conteúdo e simplicidade em sua adaptação de acordo com o tema de interesse; a facilidade no aprendizado e uso da ferramenta, tornando o professor produtor da sua aplicação; e conteúdo aberto e disponivel em repositórios na Internet.

\section{Introdução}

O ensino e a aprendizagem mediados pela tecnologia se caracterizam em importantes objetos de investigação pela comunidade científica. Tal fato se encontra consolidado pelas inúmeras pesquisas realizadas nas últimas décadas na área que, em geral, visam a apresentar variados modelos e técnicas a serem utilizados na prática docente. Dada sua dinamicidade e apelos cultural e social, a Informática na Educação conquistou seu espaço e, atualmente, se constitui em um campo de referência em pesquisas que versam sobre as mais diferentes esferas do conhecimento humano. Não obstante, segundo Tori (2010), considerando o cenário tecnológico vivenciado no cotidiano, a educação se vale de vastas abordagens com a aprendizagem pautada pelas tecnologias interativas.

Mediante a facilidade de acesso que a população tem encontrado frente às tecnologias com custo cada vez mais reduzido, explorar conteúdos e materiais disponibilizados na Internet tornou-se, para muitos, um hábito diário, sobretudo, para aqueles que foram alfabetizados no contexto dessa evolução. Logo, o uso de recursos 
educacionais que ultrapassam os limites impostos pelas barreiras geográficas e temporais torna-se uma alternativa promissora na educação, bem como os novos modos de se trabalhar a informação e o conhecimento. Ademais, a oportunidade de explorar ferramentas que promovam o incentivo e a motivação dos discentes pelos estudos dentro e fora da sala de aula se caracteriza em uma postura docente responsável e, por conseguinte, representa uma mudança necessária nos paradigmas de ensino e aprendizagem. Exemplos de pesquisas realizadas na última década que se beneficiam do uso de recursos computacionais na Internet e suas distintas abordagens nesse âmbito podem ser destacados.

Já em 2001, observa-se a preocupação em auxiliar o processo de avaliação de estudantes em ambientes de ensino a distância na web realizando ações corretivas adequadas em face de problemas encontrados nas atividades dos alunos (Musa et al. 2001). Ainda no que se refere à avaliação, a pesquisa de Otsuka e Rocha (2002) investiga experiências desenvolvidas envolvendo a avaliação formativa a distância de acordo com os interesses e objetivos pedagógicos do formador. Ainda em 2002 e no que tange à aprendizagem colaborativa, Silveira e Ferreira (2002) apresentam uma ferramenta de suporte à aprendizagem nesta modalidade por intermédio de um processo de autoria híbrida de conteúdo didático, fazendo uso de uma arquitetura de objetos distribuídos com suporte à realidade virtual. No ano seguinte, Hansen e Pinto (2003) apresentam um mecanismo que permite a integração de Web Services e recursos educacionais como forma de atenuar os conhecimentos específicos de linguagens com suporte a aplicações web para a criação de ambientes. No ramo da Inteligência Artificial, Leonhardt, Neisse e Tarouco (2003) propõem a criação de um Chatterbot educacional temático que busca imitar o comportamento da inteligência humana direcionado a jovens estudantes e adultos.

No cenário de deficiências auditivas, em 2004, a pesquisa de Rossi, Souza e Pinto (2004) apresenta o desenvolvimento de um protótipo de um fórum de discussão que utiliza a escrita da Língua Portuguesa e da Língua Brasileira de Sinais (Libras), objetivando minimizar as dificuldades de comunicação escrita entre surdos e entre surdos e ouvintes. No próximo ano, Kirner e Zorzal (2005) apresentam a criação de um ambiente colaborativo com Realidade Aumentada operando em rede para estimular a aprendizagem e o desenvolvimento de habilidades em grupo. Em 2006, a pesquisa de Schneider e Nedel (2006) propõe o desenvolvimento de um sistema dedicado ao ensino da Libras para indivíduos surdos e não surdos fazendo uso de animação de humanos virtuais.

Em relação à inclusão digital, Corrêa et al. (2006) apresentam um estudo da aceitabilidade de computadores portáteis de baixo custo na educação básica considerando os potenciais usuários, neste caso, professores e alunos. Os resultados da pesquisa evidenciaram a necessidade de uma formação específica para os professores, além de um novo planejamento das aulas para uso da tecnologia. $\mathrm{Na}$ área da Web Semântica, Isotani et al. (2008) apresentam o estado da arte sobre o uso dessa tecnologia, além da Web 2.0, no cenário educacional.

Em 2009, a pesquisa de Vieira e Santarosa (2009) analisou as motivações, necessidades e interesses de idosos com relação ao uso de tecnologias como o computador e a internet. Os principais resultados destacaram aspectos ligados à inclusão social, comunicação e atualização profissional. Explorando aspectos de hipermídia, Bueno, Brito e Brito (2011) propõem o uso de um sistema hipermídia adaptativo 
educacional que tem como objetivo a personalização do processo de ensinoaprendizagem, por meio da web, provendo adaptações do conteúdo a ser apresentado conforme a necessidade.

$\mathrm{Na}$ esfera das redes sociais, Balbino e Anacleto (2011) analisam o fenômeno desse meio tecnológico de interação social como potencial ferramenta para a extensão de práticas educativas. Assim, o trabalho apresenta um framework que objetiva estabelecer diretrizes computacionais que ofereçam suporte ao projeto de redes sociais online focadas na difusão de inovações. A recente pesquisa de Marcon, Machado e Carvalho (2012) defende que o uso das redes sociais é uma forte tendência nos processos educativos e discute a utilização do Facebook como parte de uma arquitetura pedagógica a partir de uma experiência. Ainda nesse contexto, Barcelos, Passerino e Behar (2013) constroem e analisam uma proposta de formação continuada com suporte de uma rede social na internet para egressos de um curso de licenciatura em Matemática. Como um dos principais resultados observados os autores destacam que a flexibilidade da formação e configuração de recursos da rede social permitiu atender particularidades de cada professor, além de seu contexto docente.

Neste momento, é importante destacar que independente da abordagem, segundo Kirner (2013, p. 76):

\begin{abstract}
As aplicações educacionais suportadas por computador, normalmente, são desenvolvidas por especialistas em computação, consultando profissionais de educação. Em muitos casos, as aplicações têm muito mais influência dos especialistas em computação do que dos profissionais de educação - é o uso tradicional da Tecnologia na Educação (...) Para uma aplicação ser usada na Educação Aberta, ela deve apresentar elementos que a possibilitem ser popular, envolvendo: seu uso em todas as camadas sociais, o uso de equipamentos simples e baratos ou gratuitos, o uso de software livre, o acesso intuitivo sem exigência de destreza, a capacidade de adaptação, a possibilidade de uso multisensorial, a facilidade de aprender a usá-la, sua capacidade de motivação e engajamento no tema abordado, a percepção de segurança e eficiência, a universalidade da linguagem utilizada etc.
\end{abstract}

Face a essa realidade e visando a contemplar as características esperadas em uma aplicação educacional de cunho aberto em termos de acesso, o objetivo geral desta pesquisa envolve a apresentação de um objeto de aprendizagem no contexto do ensino de variação linguística em uma aplicação educacional aberta baseada em hipermídia. Assim, o trabalho busca promover uma discussão do uso dessa abordagem com vistas a subsidiar, de forma complementar, o ensino deste tópico nas aulas de língua portuguesa.

Nesse sentido, a seção 2 discute aspectos do ensino de língua portuguesa considerando a inerente variação linguística vis-à-vis aos documentos oficiais que norteiam o ensino do tema. A seção 3 apresenta uma proposta de abordagem no contexto do ensino de variação linguística e o desenvolvimento de uma aplicação educacional online baseada em hipermídia como suporte a esse objetivo. Finalmente, a seção 4 apresenta as conclusões do trabalho, além de realizar apontamentos acerca de trabalhos futuros.

\title{
2. Materiais Didáticos e Variação Linguística
}

Com base no exposto, diversas técnicas e instrumentos de auxílio para a aprendizagem aplicados em áreas específicas são propostos continuamente. Nessa vertente, um campo 
que também pode se beneficiar das vantagens oferecidas pelo uso de ferramentas computacionais educacionais é o estudo da língua portuguesa.

A língua portuguesa, assim como as demais línguas do mundo, não é homogênea e possui caráter multifacetado, uma vez que a variação linguística é uma propriedade constitutiva das línguas naturais (Labov 1972). Ou seja, há diferentes realizações da língua que são condicionadas por variáveis diversas inerentes ao sistema linguístico ou externas a ele (Tarallo 1999). Desse modo, de acordo com o perfil do falante, da região geográfica, da classe social, do contexto comunicativo, dentre outras variáveis, os usos linguísticos serão diferenciados.

Vasta bibliografia sobre o ensino de língua portuguesa no cenário nacional aponta para a necessidade da inclusão da variação linguística no âmbito desta disciplina, conforme se verifica nos trabalhos de Bortoni-Ricardo (2004), Mattos e Silva (2004), Bagno (2007), Faraco (2008) entre outros.

Os Parâmetros Curriculares Nacionais para as séries finais do Ensino Fundamental (Brasil 1998) e para o Ensino Médio (Brasil 2000), no tocante ao ensino de língua portuguesa, asseveram que "a abordagem da norma padrão deve considerar a sua representatividade, como variante linguística de determinado grupo social, e o valor atribuído a ele, no contexto das legitimações sociais" (Brasil 2000, p.7), sem, contudo, deixar de "respeitar e preservar as manifestações da linguagem, utilizadas por diferentes grupos sociais, em suas esferas de socialização" (Brasil 2000, p. 14).

O documento que regulamenta o ensino de língua portuguesa no país reconhece a necessidade de se promover junto aos discentes uma conscientização da variação linguística e a importância da adequação da linguagem ao efetivo contexto de uso. Em outras palavras, de acordo com o documento, o ensino de língua portuguesa não se restringe apenas à propagação de regras gramaticais, mas abrange, sobretudo, $\mathrm{o}$ desenvolvimento de habilidades de leitura e produção de textos diversos, tanto na modalidade oral quanto na escrita, considerando-se, principalmente, as condições de produção e recepção desses textos.

Já no fim da década de 1970, Castilho (1978) afirmava que as pesquisas sociolinguísticas desenvolvidas até então indicavam a necessidade de mudanças no ensino de língua portuguesa. Desse modo, considerando uma gama de fatores, dentre eles a democratização do ensino, o autor afirma:

Os métodos e materiais didáticos também não mudaram ou mudaram pouco - o que em nada socorre os professores, perplexos ante a esse público, e despreparados para ele. Nesse particular, o que mais de pronto choca o observador é o fato de que os livros didáticos são surpreendentemente iguais, a despeito da diversidade dos estabelecimentos quanto ao nível de seus alunos (Castilho 1978, p.18).

Pesquisas mais recentes como as de Faraco (2008) e Bagno (2013) revelam que embora se reconheça o avanço alcançado no que diz respeito o ensino de português como língua materna, muito ainda há para ser feito, uma vez que ao se tratar de variação linguística, os materiais didáticos ainda não atingiram o ideal sociolinguístico pretendido. Segundo Faraco (2008, p. 177),

Nos livros, os fenômenos da variação são ainda marginais e maltratados (são abordados tendo a cultura do erro como pano de fundo). Quando se fala em variedades da língua, predominam referências à variação geográfica (sem 
dúvida, a mais fácil de ser abordada por envolver menos preconceitos do que a variação social). No entanto, os fenômenos são aqui apresentados muito mais de uma maneira anedótica do que como expressões linguísticas da história das comunidades de cada região.

Assim, o parecer de Faraco corrobora a opinião de que os materiais didáticos utilizados pelos professores têm se mostrado insuficientes para o tratamento da variação em sala de aula.

Bagno (2013), apresentando uma visão crítica de 24 coleções aprovadas pelo MEC no Programa Nacional do Livro Didático em sua edição de 2008 (PNLD, 2008), ratifica esta conclusão. De acordo com o autor, trata-se de "bons livros que constituem material recomendável para o ensino de língua portuguesa nas escolas públicas e que apresentam qualidades que justificam sua inclusão no programa de compras do governo", porém, no que se refere ao tópico variação linguística, o tratamento "mesmo em coleções bem avaliadas, está longe de ser satisfatório numa perspectiva mais sintonizada com uma linguística contemporânea e com os objetivos de uma educação em língua materna que favoreça o letramento dos aprendizes" (Bagno 2013, p. 11).

Neste sentido, há de se observar a necessidade de materiais complementares aos livros didáticos que poderão ser desenvolvidos pelo professor ou como atividade para os alunos a partir do uso de novas tecnologias.

\section{Produção do Objeto de Aprendizagem}

O material produzido e apresentado nesta oportunidade foi desenvolvido a partir de uma família de aplicações genéricas de hipermídia online concebida pelo professor Claudio Kirner e batizada de RE-MIIO ${ }^{1}$ (Recurso Educacional com Mídias Interativas Integradas Online) (Kirner 2013). A aplicação derivada a partir do RE-MIIO, denominada Variação Linguística Regional ${ }^{2}$, é composta por elementos de textos, sons (no formato de narrações), imagens, vídeos e páginas web. A escolha do tópico Variação Regional deuse pela necessidade de apresentar uma visão científica sobre este tipo de variação, sob a perspectiva lexical, rompendo com o caráter anedótico por vezes atribuído ao tema por alguns materiais que o abordam, conforme bem atestou Faraco (2008).

A diretriz norteadora para o desenvolvimento do RE-MIIO teve como base ações de modo a promover alterações no paradigma ainda amplamente vivenciado em que a tecnologia permeia a educação, e não o contrário. Assim, visando a este objetivo e no sentido de transformar os professores em adaptadores ou criadores de suas próprias aplicações, mesmo diante de um cenário em que esse perfil, em sua grande maioria, ocupa o papel apenas de usuário final, a comunidade científica conta, atualmente, com uma solução em que quatro características podem ser destacadas (Kirner 2013): (i) o professor torna-se o criador de sua aplicação mediante adaptações simples a partir de uma estrutura padrão; (ii) devido à separação da estrutura e conteúdo dispostos na ferramenta, o professor facilmente cria sua aplicação de acordo com o tema de estudo desejado, preenchendo ou adaptando conteúdos previamente criados; (iii) a facilidade no aprendizado e uso da ferramenta a torna uma solução poderosa na produção de conteúdos por docentes e discentes; (iv) os materiais desenvolvidos são disponibilizados

\footnotetext{
${ }^{1}$ http://www.ckirner.com/midias

2 http://sgvclin.altervista.org/varlinreg/
} 
em repositórios abertos na internet, o que facilita a disseminação dos conteúdos elaborados.

De acordo com a estrutura padrão do RE-MIIO (Kirner 2013), tem-se um objeto raiz representado por uma imagem centralizada na tela e, a partir dela, o usuário pode acessar conteúdos disponíveis em caixas, no formato de menus, que apresentam detalhes com base na preferência do criador do objeto de aprendizagem. Ao interagir com as caixas, o usuário pode acionar recursos multimídia associados a elas. Em se tratando do ensino de variação linguística, o RE-MIIO Variação Linguística Regional, objeto de estudo em questão, não explorou recursos de imagens 3D e realidade aumentada disponíveis na ferramenta original, pois, segundo os autores desta pesquisa, os referidos recursos não agregariam na compreensão dos conteúdos produzidos. Com isso, devido à flexibilidade proporcionada pela ferramenta, sua estrutura original sofreu pequenas modificações, conforme se pode observar na Figura 1.

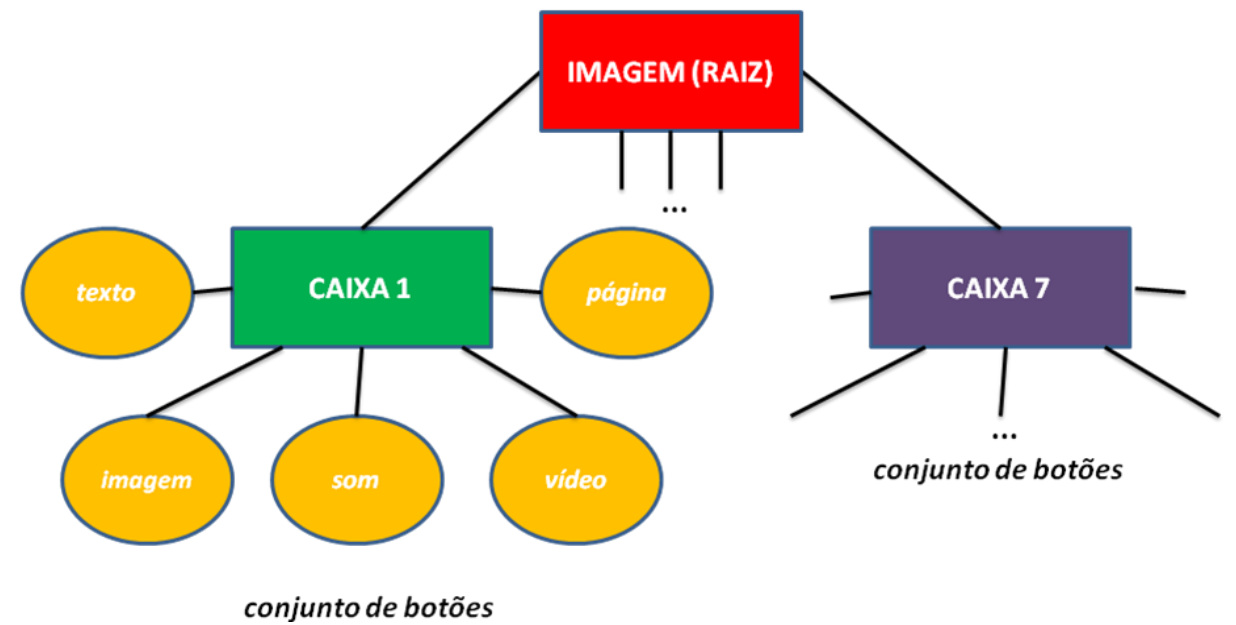

Figura 1 - Estrutura lógica do RE-MIIO Variação Linguística Regional - Adaptada de Kirner (2013). A partir da imagem raiz, o usuário pode acessar os diferentes recursos hipermídia disponibilizados no formato de menu.

Após a adaptação, a nova estrutura manteve a imagem raiz e, à sua direita, encontram-se disponíveis 7 caixas apresentadas no formato de menus deslizantes. Essa alternativa de implementação proporciona liberdade para o usuário navegar pelo conteúdo da página principal, sem sobreposição das caixas à imagem. A Figura 2 apresenta a implementação do RE-MIIO Variação Linguística Regional sob a forma de uma página na internet, com parte de seus recursos interativos visíveis.

\subsection{Conteúdo do Material}

O estudo de variação linguística envolve, dentre outras particularidades, a produção de cartas linguísticas que buscam representar a diversidade na fala de indivíduos pertencentes a determinada região, consagradas pelo método da geolinguística. Nessa linha, uma carta linguística corresponde a uma imagem (mapa) que possui dois elementos principais: (i) representação gráfica das respostas (em função da produtividade, isto é, frequência absoluta) dos informantes, para uma questão, distribuídas em uma rede de pontos (localidades); (ii) legenda com as respostas consideradas no estudo.

Dependendo do tamanho da amostra a ser investigada, o processo de elaboração de uma carta linguística torna-se trabalhoso, pois além da necessidade de os dados 
coletados serem tabulados corretamente para a devida totalização, sua representação gráfica na carta demanda tempo considerável. No sentido de facilitar o trabalho do professor, o material produzido nesta pesquisa teve como suporte a ferramenta [SGVCLin] que, a partir de uma base de dados populada com informações de variações lexicais, gera variadas cartas linguísticas que podem ser exploradas pelo docente no ensino do tema (Romano, Seabra e Oliveira 2014). Dessa forma, a carta utilizada como elemento raiz do RE-MIIO Variação Linguística Regional foi produzida por meio de um processo automatizado gerido pelo software, e demandou poucos minutos. A partir daí, coube ao docente apenas a confecção dos materiais e a abordagem didática explicativa da carta, apresentados na forma de elementos hipermídia disponíveis no RE-MIIO.

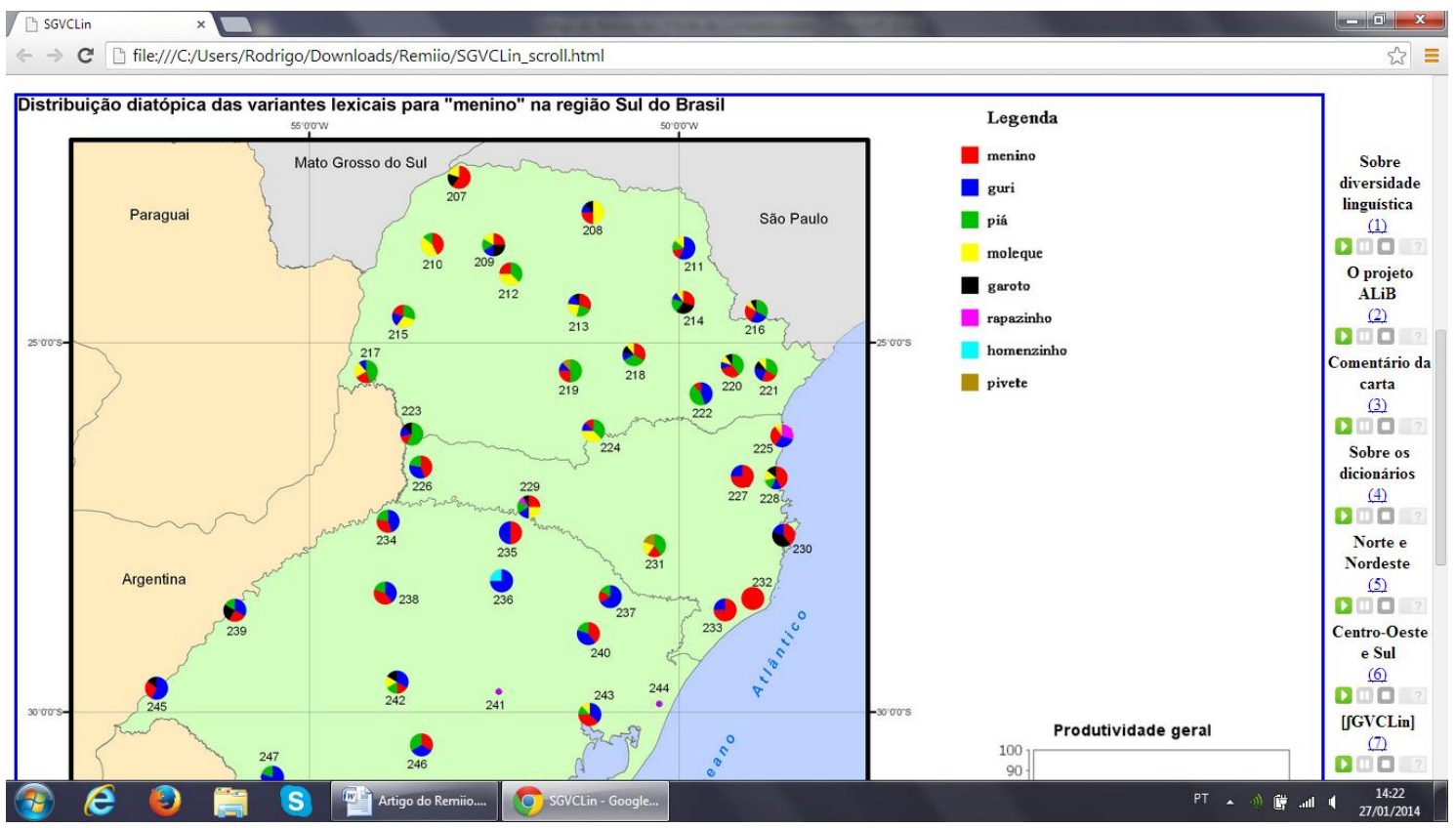

Figura 2 - Implementação do RE-MIIO Variação Linguística Regional. Na versão proposta, os menus foram disponibilizados em formato deslizante à direita da imagem raiz, proporcionando maior flexibilidade na interação do usuário.

A estrutura final desenvolvida no RE-MIIO Variação Linguística Regional contém as seguintes opções de menu:

- Sobre diversidade linguística: realiza considerações gerais sobre o fenômeno da variação linguística como uma particularidade característica das línguas naturais. Abordam-se questões do tipo: Por que as línguas variam? O que condiciona essa variação? Quais são os tipos de variação? As perguntas são respondidas por meio de linguagem simples e com diversos exemplos. São incluídos vídeos, músicas e imagens, bem como links para futuras consultas.

- O projeto ALiB: é apresentado um expressivo projeto de pesquisa desenvolvido no país - o Atlas Linguístico do Brasil (ALiB), sediado na Universidade Federal da Bahia. A partir do corpus deste projeto são explorados dados reais do português brasileiro no que se refere às denominações para "a criança de 5 a 10 anos do sexo masculino" em cidades da região sul do Brasil. São fornecidos links para futuras consultas.

- Comentário da carta: apresentam-se os comentários da imagem principal que se 
visualiza no RE-MIIO. Trata-se da carta linguística que representa a distribuição espacial dos designativos para menino em algumas cidades do sul do Brasil. Em cada um dos estados da região Sul predominam diferentes formas: piá, no Paraná; menino, em Santa Catarina; e guri, no Rio Grande do Sul. Os dados apresentados consistem em informações reais coletadas junto a 168 informantes com nível fundamental de escolaridade.

- Sobre os dicionários: definições e os comentários de dicionários gerais da língua portuguesa, desde o mais antigo (Bluteau 1712) até o mais recente (Ferreira 2004) a que se teve acesso. São acrescentadas também as informações sobre a etimologia dos vocábulos.

- Norte e Nordeste: pautando-se em outros trabalhos empíricos, apresentam-se outras cartas linguísticas que retratam os designativos no Norte e Nordeste do país. São incluídas referências para futuras pesquisas, bem como imagens.

- Centro-Oeste e Sul: o mesmo é desenvolvido para as regiões Centro-Oeste e Sul. A região Sudeste não foi incluída pelas escassez de dados referentes a pelo menos um estado completo. São incluídas referências para futuras pesquisas, bem como imagens.

- [SGVCLin]: descrição sumária do software que possibilita a geração de mapas que retratem a variação linguística geográfica. Esta opção ainda contempla a indicação de bibliografia e links para pesquisas.

\section{Considerações Finais}

Esta pesquisa apresentou detalhes inerentes ao desenvolvimento de uma proposta complementar ao ensino de variação linguística em língua portuguesa em uma aplicação educacional aberta baseada em recursos hipermídia.

Com base nos recursos oferecidos pela aplicação RE-MIIO, foi possível verificar que o ensino de variação linguística pode ser explorado utilizando modos diferenciados em sala de aula ou por meio de atividades extraclasse que vão além dos livros didáticos tradicionais habitualmente adotados. Essa realidade torna-se possível, pois, atualmente, os professores contam com tecnologias promissoras e gratuitas que podem despertar o interesse dos estudantes nas aulas, ultrapassando barreiras geográficas e temporais. A proposta de ensino apresentada nesta oportunidade mostra que o professor não especialista em tecnologia pode não só promover e distribuir o conhecimento, mas também, se caracterizar como o produtor do seu próprio material didático. Além disso, o fato de explorar diferentes mídias (visuais, sonoras etc.) na concepção do material produzido pode, inclusive, proporcionar maiores ganhos na aprendizagem de alunos que, possivelmente, apresentam diferentes estilos de aprendizagem e inteligências múltiplas, atendendo aos princípios da diversidade humana presente no âmbito escolar.

Nesse sentido, ressalta-se que as quatro características apontadas por Kirner (2013) em sua proposta e presentes tanto na versão original como nesta oportunidade foram atestadas pelo docente produtor do material elaborado - que representa o público alvo do estudo. Não obstante, visando a investigar a opinião de discentes de língua portuguesa acerca do material disponibilizado, os trabalhos futuros envolverão a elaboração de um cenário de aprendizagem envolvendo a aplicação do recurso didático desenvolvido em sala de aula. 


\section{Agradecimentos}

Os autores agradecem ao CNPq pelo financiamento ao Projeto "AIPRA - Ambiente na Internet para Professores desenvolverem Aplicações Educacionais com Realidade Aumentada" (Processo CNPq 559912/2010-2), que viabilizou o desenvolvimento deste trabalho.

\section{Referências}

Bagno, M. (2007). Nada na língua é por acaso: por uma pedagogia da variação linguística. São Paulo: Parábola Editorial.

Bagno, M. (2013). Sete erros aos quatro ventos: a variação linguística no ensino de português. São Paulo: Parábola Editorial.

Balbino, F. C.; Anacleto, J. C. (2011). Redes sociais online orientadas à difusão de inovações como suporte à extensão de práticas educativas. Anais do XXII Simpósio Brasileiro de Informática na Educação - SBIE, Aracaju, p. 830-839.

Barcelos, G. T.; Passerino, L. M.; Behar, P. A. (2013). Formação continuada com apoio de uma rede social na internet: tecnologias na prática docente de professores de matemática. Revista Brasileira de Informática na Educação - RBIE, v. 21, n. 2, p. 37-51.

Bluteau, R. (1712). Vocabulario portuguez \& latino: aulico, anatomico, architectonico. Coimbra: Collegio das Artes da Companhia de Jesus, 1712 - 1728. 8v.

Bortoni-Ricardo, S. M. (2004). Educação em língua materna: a sociolinguística na sala de aula. São Paulo: Parábola Editorial.

Bortoni-Ricardo, S. M. (2005). Nós cheguemu na escola, e agora?: sociolinguística \& educação. São Paulo: Parábola Editorial.

Brasil (1998). Parâmetros Curriculares Nacionais: terceiro e quarto ciclos do ensino fundamental - língua portuguesa. Brasília: MEC / SEF.

Brasil (2000). Parâmetros Curriculares Nacionais (Ensino Médio): parte II Linguagens, Códigos e suas Tecnologias. Brasília: MEC /SEF.

Bueno, A. M. F.; Brito, A. G. S.; Brito, L. C. (2011). Abordagem hipermídia educacional adaptativa para a personalização do processo de ensino através da web. Anais do XXII Simpósio Brasileiro de Informática na Educação - SBIE, Aracaju, p. 110-119.

Castilho, A. T. de (1978). Variação dialetal e ensino institucionalizado da língua portuguesa. Cadernos de Estudos Linguísticos. n. 1, Campinas, p. 13-20.

Corrêa, A. G. D. et al. (2006). Avaliação da aceitabilidade de um computador portátil de baixo custo por criança. Anais do XVII Simpósio Brasileiro de Informática na Educação - SBIE, Brasília, p. 288-297.

Faraco, C. A. (2008). Norma culta brasileira: desatando alguns nós. São Paulo: Parábola Editorial.

Ferreira, A. B. de H. (2004). Novo dicionário da língua Portuguesa. $3^{\mathrm{a}}$ ed., Versão eletrônica 5.0.

Hansen, R. P.; Pinto, S. C. C. S. (2003). Construindo ambientes de educação baseada na web através de web services educacionais. Anais do XIV Simpósio Brasileiro de Informática na Educação - SBIE, Rio de Janeiro, p. 61-70.

Isotani, S. (2008). Web 3.0 - os rumos da web semântica e da web 2.0 nos ambientes 
educacionais. Anais do XIX Simpósio Brasileiro de Informática na Educação - SBIE, Fortaleza, p. 785-795.

Kirner, C. (2013). A educação permeando a tecnologia em aplicações educacionais abertas baseadas em hipermídia e realidade aumentada. Revista Contemporaneidade, Educação e Tecnologia, v. 1, n.3, p. 76-87.

Kirner, C.; Zorzal, E. R. (2005). Aplicações educacionais em ambientes colaborativos com realidade aumentada. Anais do XVI Simpósio Brasileiro de Informática na Educação - SBIE, Juiz de Fora, p. 114-124.

Labov, W. (1972). Sociolinguistic pattens. Philadelphia: University of Pennsylvania Press.

Leonhardt, M. D.; Neisse, R.; Tarouco, L. M. R. (2003). MEARA: um Chatterbot temático para uso em ambiente educacional. Anais do XIV Simpósio Brasileiro de Informática na Educação - SBIE, Rio de Janeiro, p. 81-88.

Marcon, K.; Machado, J. B.; Carvalho, M. J. S. (2012). Arquiteturas pedagógicas e redes sociais: uma experiência no Facebook. Anais do XXIII Simpósio Brasileiro de Informática na Educação - SBIE, Rio de Janeiro.

Mattos e Silva, R. V. (2004). O português são dois: novas fronteiras, velhos problemas. São Paulo: Parábola Editorial.

Musa, D. L. et al. (2001). Agente para auxílio a avaliação de aprendizagem em ambientes de ensino na web. Anais do XII Simpósio Brasileiro de Informática na Educação - SBIE, Vitória, p. 200-206.

Otsuka, J. L.; Rocha, H. V. (2002). Avaliação formativa em ambientes de EaD. Anais do XIII Simpósio Brasileiro de Informática na Educação - SBIE, São Leopoldo, p. 146156.

Romano, V. P.; Seabra, R. D.; Oliveira, N. (2014). [ SGVCLin] - Software para geração e visualização de cartas linguísticas. RELIN: Revista de Estudos da Linguagem, Belo Horizonte, v. 22, n. 1, p.119-151.

Rossi, D.; Souza, V. C.; Pinto, S. C. C. S. (2004). Sign WebForum: um fórum de discussão que utiliza a troca de mensagens em libras na web. Anais do XV Simpósio Brasileiro de Informática na Educação - SBIE, Manaus, p. 259-268.

Silveira, I. F.; Ferreira, M. A. G. V. (2002). Implementando Vygotsky com PIAGET: autoria híbrida de conteúdo didático em um ambiente virtual distribuído de apoio à aprendizagem colaborativa a distância. Anais do XIII Simpósio Brasileiro de Informática na Educação - SBIE, São Leopoldo, p. 368-376.

Tarallo, F. (1999). A pesquisa sociolinguística. Série Princípios. 6. Ed. São Paulo: Ática.

Tori, R. (2010). Educação sem distância: as tecnologias interativas na redução de distâncias em ensino e aprendizagem. São Paulo: Editora Senac São Paulo.

Vieira, M. C.; Santarosa, L. M. C. (2009). O uso do computador e da internet e a participação em cursos de informática por idosos: meios digitais, finalidades sociais. Anais do XX Simpósio Brasileiro de Informática na Educação - SBIE, Florianópolis. 